work at the Government Test House as well as the work of the Bureau (Delhi : Manager of Publications, 1937. 14 annas; 1s. 6d.) The Industrial Research Council is an advisory body, consisting of representatives and non-official nominees of the central, provincial and leading State Tovernments, which meets once a year to discuss policy in the co-ordination and development of research. Programmes for road research have been approved by the Council, and the development of the manufacture of casein plastics has been considered both by the Council and by the Bureau. Industrial standardization and the compilation of a list of researches in progress or contemplated in industrial laboratories are also receiving attention, and a number of prizes have been awarded by the Council for papers bearing on industrial development. The research branch of the Government Test House which deals with the research programmes suggested by the Council and other problems referred to the Bureau has completed a preliminary investigation on the characteristics which affect the setting of red lead paint. For accelerated weathering tests on various paints the weatherometer, modified to give test conditions approximately to outside weather conditions at Alipore, has been used.

SPECIAL apparatus has also been developed in India for accelerated life tests on dry cells and considerable attention has been devoted to the use of vegetable oils for internal combustion engines. A process has been developed for rendering castor oil mi cible with mineral oils of known suitability for use in such engines, and the effects of various antioxidants have been investigated. Steady progress has been made with the work of modifying the Morris and Lister engines and of equipping them with accessories to render the operating conditions fully controllable. Another section has been responsible for important investigations on the properties of petral-benzole mixtures and the effect of changes in the composition of the benzole. A number of investigations on sand, lime, surkhi, clay, etc., have been initiated. Good progress has been made with the design of the equipment for the proposed road test track at Calcutta. Separate chapters in the report deal with work on glass and on oils and soaps, the former including the improvement of glass furnaces and a survey of glass-making materials.

\section{Research in the Iron and Steel Industry}

AT the request of the Board of Trade, the Import Duties Advisory Committee has conducted an inquiry into "The Present Position and Future Development of the Iron and Steel Industry", and its report, which is full of interest, has now been issued (Cmd. 5507. London: H.M. Stationery Office, 1937. 2s. net). The report is essentially concerned with economic conditions, but its authors recognize that both the present and the future of the industry are closely bound up with scientific control and research. They express their satisfaction with the provision made for research and their hope that it will be further extended in the future. The total industrial subscription to the Iron and Steel Industrial Research Council for $1936-37$ is estimated as $£ 30,000$. As the capital of the concerns estimated to be responsible for 86 per cent of the country's output of steel in 1936 is given as $£ 126.7$ millions, this cannot be considered an excessive allowance. Several of the large steel concerns have their own research laboratories, involving a considerable expenditure, and these have actively collaborated in the investigations of the Council, thus making an indirect contribution. Full particulars of the research organization were furnished to the Committee by the Department of Scientific and Industrial Research in writing, but the seventy-three witnesses examined orally did not include a scientific metallurgist or a director of a research laboratory, and one would have welcomed a fuller appreciation in the report of the fact that the economies to be effected by scientific improvements-as, for example, in the field of refractoriesare as important as the improvements in organization to which the report, thorough as it is, is almost entirely devoted.

\section{Far Eastern Conference on Rural Hygiene}

A CoNFERENCE for Far Eastern countries on this subject was opened on August 3 by the GovernorGeneral at Bandoeng, Java. This Conference was arranged by the League of Nations Health Organisation under the presidency of Dr. T. Offringa, director of the Netherlands Indies Public Health Service, with Dr. J. Rajchman, medical director of the League Health Committee, as secretary, assisted by Dr. C. L. Park, director of the Eastern Bureau of the Health Organisation. The Conference is meeting in five sections, in which the following subjects will be discussed: ( 1 ) health and medical services: the advantages and disadvantages of training 'semiqualified' or assistant doctors to assist the qualified medical staff, and possible alternatives; (2) rural reconstruction and collaboration of the population, with the view of improving conditions of life in rural districts, a policy favoured by the Government of India and other countries; (3) sanitation and sanitary engineering, including housing, water supply, latrines, refuse disposal and fly control ; (4) nutrition, a subject of importance in the East, for it has been estimated that 75 per cent of the population of Asiatic countries exist on a diet below the standards fixed by European science; (5) measures necessary to combat specific diseases, such as malaria, plague, tuberculosis, hookworm infection, yaws and leprosy, and mental diseases; also drug addiction.

\section{The Science Museum}

BesIdes the usual statistical information regard. ing the number of visitors and attendances at lectures, notes on special exhibitions, on acquisitions and the progress of the five main divisions of the Museum, the annual report of the Advisory Council of the Science Museum for 1936 is of especial interest as it contains a review of the growth and activities 